\title{
Challenges and Achievements of Medical Tourism from the viewpoint of Medical tourists and Service Providers in the Public Hospitals of Shiraz (20017)
}

\author{
Research Article
}

\section{Khadijeh Ghanbari $^{1}$, Abbas Yazdanpanah ${ }^{1 *}$, Parviz Aghaei ${ }^{2}$}

1. Department of Healthcare Management, Marvdasht Branch, Islamic Azad University, Marvdasht, Iran 2. Department of Health Services Administration, South Tehran branch, Islamic Azad University, Tehran, Iran.

\begin{abstract}
Introduction: Obviously, medical tourism is growing rapidly. This study aimed to identify the challenges and achievements of medical tourism from the viewpoint of medical tourists and service providers in the public hospitals of Shiraz in 2007. Method: This descriptive study was carried out through structural and thematic analysis, using a method called SWOT. The study sample included all tourists, medical tourists, and service providers in the public hospitals of Shiraz. Accordingly, 21 medical staff and 31 medical tourists were investigated. The Friedman Test was used to prioritize and rank the most important weaknesses, strengths, opportunities, and threats of medical tourism. Results: The results showed that medical tourism in the public hospitals of Shiraz had 9 strengths, 8 weaknesses, 8 opportunities, and 6 threats. A total of 17 strategies, including four SO strategies, three ST strategies, six WO strategies, and four WT strategies for medical tourism in the public hospitals of Shiraz were developed. Some of the major parts of these strategies included the development of medical tourism in the public hospitals of Shiraz, the establishment of medical justice for medical tourists through the optimal distribution of services and control over price and quality, the fight against corruption and collusion, plans for supporting the officials, financial support and investment in the medical tourism sector, and the development of strategic plans for supporting medical tourism. Conclusion: It seems that appropriate policies should be legislated by the Ministry of Health and Medical Education to improve the medical tourism in Shiraz.
\end{abstract}

Keywords: Medical tourism, Public hospital, Shiraz.

\section{Introduction}

As a branch of health tourism, medical tourism represents a fast growing industry in which patients travel across international boundaries to obtain medical services (1). Meanwhile, countries succeeding in attracting this massive capital provide high-quality services at a larger scale, in addition to low prices for services, qualified physicians, and beautiful and attractive landscapes.

In fact, not only is tourism the largest industry in the world, it is also growing day by day. As the World Tourism Organization predicts, the number of tourists will reach 1.5 billion people in 2020 (2).

The number of people who use medical and treatment services is increasing significantly. Moreover, these services are exported in larger scales in the world, being doubled from 1997 to 2003. This global increase is ten times faster than foreign tourism revenues and five times faster than global exports of services (3).

Medical care services accounted for $0.73 \%$ of the global trade in 2003 , while it was $0.38 \%$ in 1997 . These services accounted for $40 \%$ of the global trade in 2003 in developing countries (4). About four million international patients around the world are provided

*Corresponding Author:

\section{Abbas Yazdanpanah}

Department of Healthcare Management,

Marvdasht Branch, Islamic Azad University,

Marvdasht, Iran.

Email id:abbas_yaz@miau.ac.ir with such services annually. It is estimated that they worth as much as $\$ 60$ billion. Asia accounts for about 7 billion dollars of this trade (5). Medical tourism is thought to account for $5 \%$ of the global tourism. Overall, this market is big and developed. This global trade which is worth 60 billion dollars grows up to $20 \%$ annually (6).

Iran is among the top ten countries in terms of tourist attraction. According to the plans, 30\% of the medical needs of the country should be provided through the export of medical goods and services and tourism by the end of the fourth development plan. In addition to the need for the export of medical goods and services, medical tourism income can also be beneficial for developing countries, especially Asian countries (7). This income has led some Asian countries such as Singapore, Thailand, and India to significantly advertise their medical services among the world's patients. However, inexpensive medical services, proper quality of services, and the newest medical methods can boost medical tourism in Iran.

With huge medical capacities, Shiraz is one of the target markets of Iran in medical tourism. Shiraz is also home to Hafez and Saadi, two of the most prominent poems. Known as a historic and cultural city, Shiraz has huge medical capacities and can be regarded as one of the target markets of Iran in medical tourism. This city can also bring high foreign exchange income to the country and region. With more than dozens of wellequipped and specialized academic, charity, and private hospitals, the city offers a wide range of medical services by experienced and skilled physicians. 
Therefore, the present research aims to identify the challenges and achievements of medical tourism from the viewpoint of the medical tourists and service providers in the public hospitals of Shiraz in 2017.

\section{Materials and Methods}

This descriptive study was carried out through structural and thematic analysis. The study sample included all tourists, medical tourists, and service providers in the public hospitals of Shiraz. Accordingly, 21 medical staff and 31 medical tourists were investigated. They were selected based on goal-oriented or purposive sampling and snowballing method.

In order to collect the views of these people in a semi-structured manner, in-depth interviews were conducted.

The interview duration was predicted in advance and coordinated with the individuals either by telephone or in person. Moreover, they were given explanations about the purpose of the interviews. They were also assured that the data and their remarks would be kept fully confidential. Despite their initial agreement, they were allowed to withdraw from the interview at any time they wished. All interviewees who were voluntarily willing to cooperate completed and signed the written consent form.

During the interviews, the sessions were recorded through two MP3 recorders to avoid possible problems. The recordings were then analyzed in order to know when the data were saturated. The analysts aimed to increase the accuracy of the text analysis immediately after the end of each session.

\section{Data Analysis}

Descriptive statistics was used to analyze the data and describe the demographic characteristics. For the inferential statistics, Friedman Test was used to rank the strengths, weaknesses, opportunities, threats, and longterm goals. For the strategic analysis, internal evaluation matrix was used to compare strengths and weaknesses. Also, the external evaluation matrix was utilized to compare opportunities and threats. Besides, the internal and external evaluation matrices were used to determine the strategic position. Finally, the SWOT analysis which was based upon intuitive judgment was used to determine the WT, WO, ST, and SO strategies.

\section{Results}

Tables 1-3 show the results of this study. According to the results, medical tourism has different strengths, weaknesses, threats, and opportunities in the public hospitals of Shiraz. According to SWOT analysis, a total of 17 strategies including four SO strategies, three ST strategies, six WO strategies, and four WT strategies for medical tourism in the public hospitals of Shiraz were developed.

Additionally, the results of internal and external matrix indicate that medical tourism in the public hospitals of Shiraz is strategically located in the SO region; thus, medical tourism has strengths and opportunities, respectively, in terms of its internal and external factors.

Table 1. Mean rankings in the Friedman Test (Strengths of Medical Tourism)

\begin{tabular}{|l|c|c|c|}
\hline Strengths & Mean & Standard Deviation & Mean Rankings \\
\hline $\begin{array}{l}\text { The availability of appropriate medical infra- } \\
\text { structure }\end{array}$ & 2.9038 & 1.15910 & 5.28 \\
\hline Access to the public hospitals of Shiraz & 2.00 & 0.81349 & 5.00 \\
\hline Inexpensive and affordable medical care & 3.11351 & 0.87223 & 6.48 \\
\hline Diverse and high-quality medical services & 2.4038 & 1.05272 & 4.03 \\
\hline $\begin{array}{l}\text { Good ranking in the organ transplantation and } \\
\text { providing advanced and complex medical treat- }\end{array}$ & 2.3654 & 0.81719 & 4.08 \\
\hline Less time needed for medical services & 2.6154 & 0.88901 & 4.65 \\
\hline $\begin{array}{l}\text { The experienced human resources at all levels of } \\
\text { medical services }\end{array}$ & 3.4902 & 1.20619 & 6.64 \\
\hline Affordable accommodation and transportation & 2.7600 & 1.11685 & 5.15 \\
\hline Historical tourism sites in Shiraz & 2.2308 & .83114 & 3.70 \\
\hline
\end{tabular}


Table 2. Mean rankings in the Friedman Test (Weaknesses of medical tourism)

\begin{tabular}{|l|c|c|c|}
\hline \multicolumn{1}{|c|}{ Weaknesses } & Mean & Standard Deviation & Mean Rankings \\
\hline Lack of proper governmental support & 2.3529 & 1.054135 & 5.43 \\
\hline $\begin{array}{l}\text { Lack of effective coordination between custodian } \\
\text { organizations such as the Cultural Heritage, } \\
\text { Handicrafts and Tourism, and the Ministry of } \\
\text { Medical }\end{array}$ & 2.6346 & 1.06695 & 6.47 \\
\hline Low-quality medical standards in some hospitals & 2.4231 & 0.91493 & 5.65 \\
\hline $\begin{array}{l}\text { Lack of comprehensive and integrated information } \\
\text { system }\end{array}$ & 2.4808 & 0.98000 & 5.91 \\
\hline $\begin{array}{l}\text { Lack of effective coordination between different } \\
\text { departments, such as: transportation, hotels, } \\
\text { hospitals, travel agencies, etc. }\end{array}$ & 2.3654 & 0.84084 & 5.59 \\
\hline $\begin{array}{l}\text { Weak marketing and advertising system and the } \\
\text { lack of organizations and companies associated } \\
\text { with medical tourism }\end{array}$ & 2.2885 & 0.69555 & 5.53 \\
\hline $\begin{array}{l}\text { Variable prices of medical and health services in } \\
\text { some hospitals }\end{array}$ & 2.3654 & 0.71480 & 5.36 \\
\hline $\begin{array}{l}\text { Financial weakness in health care section and } \\
\text { medical tourism }\end{array}$ & 2.3846 & 0.71822 & 5.47 \\
\hline $\begin{array}{l}\text { Lack of a specific departments in the public } \\
\text { hospitals for clients who come from cities other } \\
\text { than Shiraz }\end{array}$ & 2.6731 & 0.67798 & 6.76 \\
\hline $\begin{array}{l}\text { Lack of necessary and legal guidelines for medical } \\
\text { tourists who refer to the public hospitals of Shiraz }\end{array}$ & 2.6538 & 0.73790 & 6.53 \\
\hline $\begin{array}{l}\text { Lack of specific programs for developing medical } \\
\text { tourism in the public hospitals of Shiraz }\end{array}$ & 3.0192 & 1.17974 & 7.29 \\
\hline
\end{tabular}

Table 3. Mean rankings in the Friedman Test (Opportunities of Medical Tourism)

\begin{tabular}{|l|c|c|c|}
\hline \multicolumn{1}{|c|}{ Opportunities } & Mean & Standard Deviation & Mean Rankings \\
\hline Affordable prices for medical and health services & 3.0577 & 0.99830 & 11.16 \\
\hline $\begin{array}{l}\text { Creating and enhancing job opportunities by } \\
\text { letting medical tourists to Shiraz }\end{array}$ & 2.5000 & 0.98020 & 8.16 \\
\hline $\begin{array}{l}\text { With increasing demand for medical tourism, } \\
\text { provincial authorities will support medical tourism } \\
\text { to a greater extent. }\end{array}$ & 3.2885 & 1.03538 & 11.82 \\
\hline Using new technologies to attract tourism & 2.4231 & 0.95684 & 8.00 \\
\hline $\begin{array}{l}\text { Using Shiraz's medical capacities in combination } \\
\text { with non-medical tourism }\end{array}$ & 3.3462 & 0.92640 & 12.67 \\
\hline $\begin{array}{l}\text { Employing labor forces and reducing } \\
\text { unemployment in Shiraz }\end{array}$ & 2.51352 & 0.89134 & 8.89 \\
\hline
\end{tabular}

Table 4. Mean rankings in the Friedman Test (Threats of Medical Tourism)

\begin{tabular}{|l|c|c|c|}
\hline \multicolumn{1}{|c|}{ Threats } & Mean & Standard Deviation & Mean Rankings \\
\hline $\begin{array}{l}\text { Authorities neglect the development and attraction } \\
\text { of tourism as a source of capital. }\end{array}$ & 2.6800 & .89077 & 5.53 \\
\hline $\begin{array}{l}\text { Intense competitions between major cities in at- } \\
\text { tracting medical tourism }\end{array}$ & 2.7200 & 1.06981 & 5.59 \\
\hline $\begin{array}{l}\text { Limited capabilities of human resource in infor- } \\
\text { mation skills }\end{array}$ & 2.6600 & 1.08063 & 5.35 \\
\hline $\begin{array}{l}\text { Bribery and collusion in the medical and health } \\
\text { sector }\end{array}$ & 2.7600 & 1.15281 & 5.23 \\
\hline $\begin{array}{l}\text { The fact that expert physicians migrate to major } \\
\text { big cities. }\end{array}$ & 2.7200 & 0.92670 & 5.56 \\
\hline $\begin{array}{l}\text { Prioritizing other major cities in attracting medical } \\
\text { tourism }\end{array}$ & 2.5294 & 0.80878 & 4.81 \\
\hline
\end{tabular}




\section{Discussion and conclusion}

\section{The strengths of medical tourism in the public hospitals of Shiraz.}

The results showed that the medical tourism in the public hospitals of Shiraz had the following strengths: The experienced human resources at all levels of medical services; low and cost-effective health care services; the availability of appropriate medical infrastructure, affordable accommodation and transportation; low waiting time for medical services; diverse and high-quality health care services; good ranking in the organ transplantation and the reputation and expertise of physicians for providing advanced and complex medical treatment; the historical tourism sites in Shiraz, and access to the public hospitals of Shiraz.

\section{The weaknesses of medical tourism in the public hospitals of Shiraz}

The results showed that medical tourism in the public hospitals of Shiraz had the following weaknesses: The lack of plans for the development of medical tourism; the lack of specific departments in the public hospitals for patients who come from cities other than Shiraz; the lack of legal guidelines for medical tourists; the lack of coordination between the organization such as Cultural Heritage, Handicrafts and Tourism, and Ministry of Health; the lack of comprehensive and integrated information system; low medical standards in some hospitals; financial weakness in health care sectors and medical tourism; the lack of effective coordination among departments such as transportation, hotels, hospitals, travel agencies, etc.; variable prices of medical and health services in some hospitals; the lack of proper governmental support; weak marketing and advertising system; and the lack of organizations and companies associated with medical tourism.

\section{The opportunities of medical tourism in the public hospitals of Shiraz}

The results showed that medical tourism in the public hospitals of Shiraz had the following opportunities: Affordable prices for medical and health services; creating and enhancing job opportunities by letting medical tourists to Shiraz; the fact that with increasing demand for medical tourism, provincial authorities will support medical tourism to a greater extent; using new technologies to attract tourism; using Shiraz's medical capacities in combination with nonmedical tourism; employing labor forces and reducing unemployment in Shiraz; rising the interactions between medical services providers; and familiarity of different races of Iran with culture and literature of Fars and Shiraz for attracting tourists.

\section{The threats of medical tourism in the public hospitals of Shiraz}

The results showed that medical tourism in the public hospitals of Shiraz faced the following threats: The intense competition between major cities in attracting medical tourism; the fact that expert physicians migrate to major big cities.; the fact that authorities neglect the development and attraction of tourism as a source of capital.; limited capabilities of human resource in information skills; and bribery and collusion in the medical and health services sector.

\section{The internal and external factor evaluation matrix}

The results showed that medical tourism in the public hospitals of Shiraz has a score of 2.610 based on the internal factor evaluation matrix; therefore, it has several strengths in terms of internal factors. Moreover, the score is 2.565 based on the external factor evaluation matrix. Overall, based on the internal and external factor evaluation matrix, which is calculated by the comparison between the internal and external factors, medical tourism is located in the SO region for the public hospitals of Shiraz.

In the medical tourism, the following research studies have been carried out:

Fakhredini et al. (2012) evaluated the satisfaction of medical tourists and prioritized the factors influencing it, suggesting that appropriate equipment and quality of treatment are much more important in medical tourism. In the present study, it was found that managers and tourists gave priority to the experienced human resources at all levels. In contrast to Fakhredini et al. (2012), the diversity and quality of services were not of top priority in this study. It can be attributed to the fact that the present study aimed to investigate the public hospitals of Shiraz (8). Bafchizadeh et al. (2012) examined the most important challenges and opportunities of international medical services from the point of view of the experts. According to the results, the lack of regulations for supporting the patients' rights is one of the weaknesses of overseas tourism. In the present study, it was found that lack of necessary guidelines for medical tourists referring to the public hospitals of Shiraz is one of the main weaknesses in medical tourism. It seems that managers and authorities need to provide appropriate and legal guidelines in order to develop medical tourism in Shiraz, especially in public hospitals (9).

Goodarzi et al. (2013) investigated and evaluated the factors influencing the development of medical tourism in the metropolitan city of Shiraz. The results showed that quality, culture, facilities, equipment, and information and communication technology are positively and directly associated with the development of medical tourism. However, price is negatively and inversely associated with the development of medical tourism. In the present study, it was also found that one of the most important strengths of medical tourism in the public hospitals of Shiraz is the affordability of medical care (10). In a study entitled "Medical Tourism in Turkey: Opportunities and Threats", Omay and Changiz (2013) concluded that the strengths included having relatively cheaper services of medical tourism than other countries, advanced regulations, and public support. In contrast, the weaknesses included poor cooperation between medical tourism institutions, lack of a comprehensive public policy on medical tourism management and the lack of information systems to share data with the Ministry of Health. Brain drain was regarded as the most important threat in which Turkish physicians choose to immigrate to other countries. The results are in good agreement with those obtained by 
these researchers. In the present study, one of the important strengths of medical tourism in the public hospitals of Shiraz was affordable medical care. Unlike the Omay and Changiz (2013), this study considers lack of proper public support a main weakness (11).

It seems that lack of infrastructure to provide standard services is an important barrier to medical tourism (12). It is necessary to develop and implement a common strategy among the players of the medical tourism industry. Moreover, lack of the National Council for medical tourism in Iran can hinder the proper development of this industry. This is especially important for Shiraz because lack of this council can impose irreparable damage to the medical tourism (13, 14).

\section{Conclusion}

It seems that appropriate policies should be legislated by the Ministry of Health, Treatment and Medical Education to promote medical tourism in Shiraz. Moreover, it is necessary to develop a comprehensive document on medical tourism so that people from other cities can have access to medical facilities. It is also argued that supporting the officials can help create a link between medical tourism and historical and cultural tourism. For this purpose, unemployment can also be addressed to some extent. It seems that a new field of study called medical tourism can help identify the strengths, weaknesses, threats, and opportunities.

\section{References}

1. Carrera, P. M., \& Bridges, J. F. (2006). Globalization and medical care: understanding medical and medical tourism. Expert review of pharmacoeconomics \& outcomes research, 6(4), 447-454.

2. Hopkins, L., Labonté, R., Runnels, V., \& Packer, C. (2010). Medical tourism today: what is the public of existing knowledge. Journal of public medical policy, 31(2), 185-198.

3. Harryono, M., Huang, Y. F., Miyazawa, K., \& Sethaput, V. (2006). Thailand medical tourism cluster. Harvard Business School (vol./pages).
4. Lautier, M. (2008). Export of medical services from developing countries: the case of Tunisia, Social Science \& Medicine, 67: 101-10.

5. Snyder, J., Crooks, V., \& Turner, L. (2011). Issues and challenges in research on the ethics of medical tourism: Reflections from a conference. Journal of Bioethical Inquiry, 8(1), 3-6.

6. Horowitz, M., Rosensweig, J. (2011). Medical tourism vs., traditional international medical travel: a tale of two models, International Medical Travel Journal 3, 30-33.

7. Faramarzi, Alpha (2011), Medical Tourism, The Scientific Database for Management. www.system.persianblog.com

8. Mirfakhreddini Sayed Heydar, Mirfakhreddini Faezeh Sadat, \& Sadrbaghighi Seyyed Mehdi. (1391). An Investigation into the Satisfaction Rate of Medical Tourists in Yazd and Prioritizing the Factors Influencing it by Fuzzy TOPSIS, Scientific Journal of Yazd Shahid Sadoughi University of Medical Sciences, 20-5, 668-678.

9. Sherbafchi Zadeh Nasrin, Azami Saeed Reza, Bastani Peyvand (2014). "Challenges and opportunities in the medical system of the Islamic Republic of Iran: A Qualitative Approach." 1-11.

10. Goodarzi, Taghvaei, \& Zangi Abadi. (2012). An investigation into the factors affecting the development of medical tourism in the metropolitan area of Shiraz. Tourism Management Studies, 8 (23), 1-25.

11. Omay, E. G. G., \& Cengiz, E. (2013). Medical Tourism in Turkey: Opportunities and Threats. Mediterranean journal of social sciences, 4(10), 424.

12. Chee, H. L. (2007). Medical tourism in Malaysia: international movement of medical care consumers and the commodification of medical care.

13. Nagarajan, G. S. (2004). Medical tourism in India: strategy for its development. Banglore: Crisil young leader series, 10, 13.

14. Gonzales, A., Brenzel, L., \& Sancho, J. (2001). Medical tourism and related services: Caribbean development and international trade. Final report, 57-8. 